\title{
Carcinoma epider móide esofágico em paciente com esôfago de B arret: relato de caso
}

\author{
Squamous cell esophageal cancer in patient with Barret's esophagus: case report
}

Fábio da Silva Gomes', Celso Schuler², Fernando Delgiovo², Nelson Perelman Rosenberg ${ }^{3}$

\section{Resumo}

O carcinoma epidermóide de esôfago é a neoplasia esofágica mais comum no nosso meio, tendo como principais fatores de risco o etilismo e o tabaco. Há um aumento na incidência de casos de adenocarcinoma esofágico em países ocidentais, e a sua associação com o esôfago de Barret é bem estabelecida. N esse relato, apresentamos 0 caso de uma paciente com esôfago de Barret na qual foi diagnosticada a presença de carcinoma epidermóide associado à metaplasia intestinal. São raros os casos descritos na literatura com esse achado. 0 s autores apresentam o caso e revisam as publicações prévias de casos semelhantes.

Palavras-chave: Esôfago de Barret; Carcinoma epidermóide; N eoplasias esofágicas.

\begin{abstract}
The squamous cell esophageal cancer is the most common neoplasia of the esophagus, and the main risk factors known are alchool and tobacco use. In the developed countries, the incidence of adenocarcinoma of the esophagus had been increased, and it association with Barret's esophagus is well established. In this report, we present the case of a patient with Barret's esophagus and the diagnosis of squamos cell esophageal cancer associated with intestinal metaplasia. This very rare association has few reports in the literature. The authors report the case and review the index publications of similar cases.
\end{abstract}

Key words: Barret's esophagus; Squamous cell carcinoma; Esophageal neoplasms.

${ }^{1}$ M édico residente do Serviço de Cirurgia Vascular e ex-residente do Serviço de Cirurgia Geral do H ospital N ossa Senhora da Conceição

${ }^{2}$ Cirurgião torácico, ex-residente do Serviço de Cirurgia Torácica do H ospital N ossa Senhora da Conceição

${ }^{3}$ Chefe do Serviço de Cirurgia Torácica do H ospital N ossa Senhora da Conceição - M inistério da Saúde

Endereço para correspondência: Fábio da Silva Gomes - Rua Liberdade, 471 - Porto Alegre - RS - CEP: 90 420-090. E-mail: fabiogomes@voyager.com.br 


\section{INTRO DUÇÃO}

0 carcinoma epidermóide de esôfago corresponde à maioria das neoplasias esofágicas no nosso meio. Sua incidência é amplamente variável de acordo com cada região, sendo bastante alta em certas áreas de países como C hina, Japão e África do Sul. 0 tabagismo e o etilismo são os principais fatores associados a esse tipo de neoplasia, além de outros fatores comportamentais, genético/familiares, nutricionais e geográficos ${ }^{1}$. N os países ocidentais, há um crescimento na incidência de adenocarcinomas esofágicos, podendo chegar a mais de $50 \%$ dos casos ${ }^{2}$. A associação do adenocarcinoma de esôfago com a doença do refluxo gastro-esofágico e 0 esôfago de Barret, apesar de ainda não bem compreendida, já é bem estabelecida, podendo considerar-se o esôfago de Barret como uma lesão precursora do adenocarcinoma ${ }^{1,3}$. Além disso, um estudo de caso-controle realizado na Suécia e publicado em 1999, demonstrou uma forte associação entre os sintomas de refluxo gastro-esofágico e o risco de adenocarcinoma de esôfago, mesmo sem a presença de metaplasia de Barret 4 .

N este relato, apresentamos o caso de uma paciente com diagnóstico de esôfago de Barret que desenvolveu carcinoma epidermóide juntamente à metaplasia intestinal no esôfago distal.

\section{RELATO DO CASO}

Paciente do sexo feminino, 68 anos, branca, viúva, do lar, natural de São Francisco de Assis e procedente de Alvorada. Iniciou com disfagia para alimentos sólidos associado à sensação de plenitudepós-prandial eeructações freqüentes há aproximadamente 1 ano. Procurou atendimento em sua localidade onde realizou endoscopia digestiva alta na qual foi evidenciado epitélio tipo metaplasia intestinal (esôfago de Barret) na porção esofágica inferior. Fez uso de omeprazol durante 60 dias, com resolução parcial dos sintomas. Há 2 meses passou a apresentar piora da sintomatologia, quando realizou nova endoscopia digestiva alta que demonstrou lesão estenosante e ulcerada em terço esofágico inferior (figura 1). A biópsia da lesão diagnosticou carcinoma epidermóide associado à metaplasia de Barret (figura 2).

Paciente ex-tabagista, tendo fumado $1 / 2$ carteira de cigarros por dia durante 10 anos, parou de fumar há aproximadamente 8 anos. Sem história de etilismo ou perda ponderal. $\mathrm{H}$ istória familiar negativa para tumor esofágico ou outras patologias. Ao exame físico, apresenta-se em bom estado geral, sem achados relevantes.

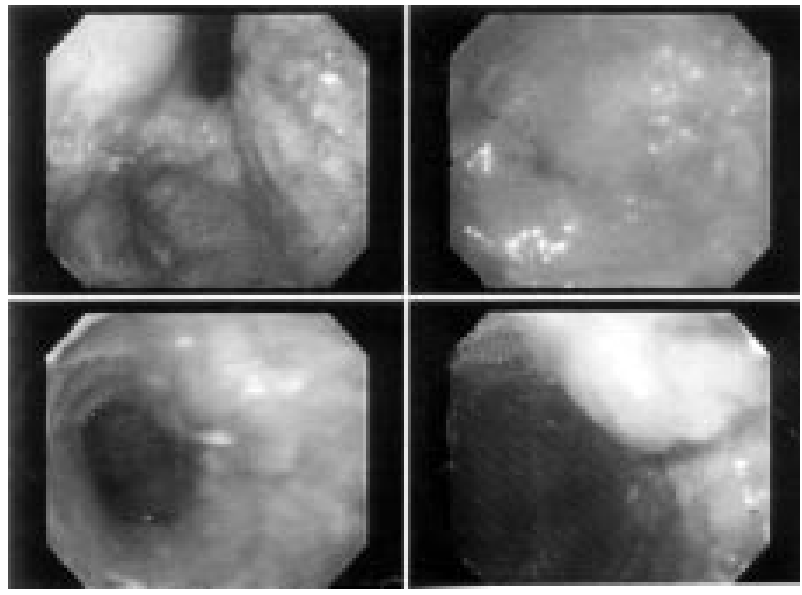

Figura 1- Endoscopia Digestiva Alta.

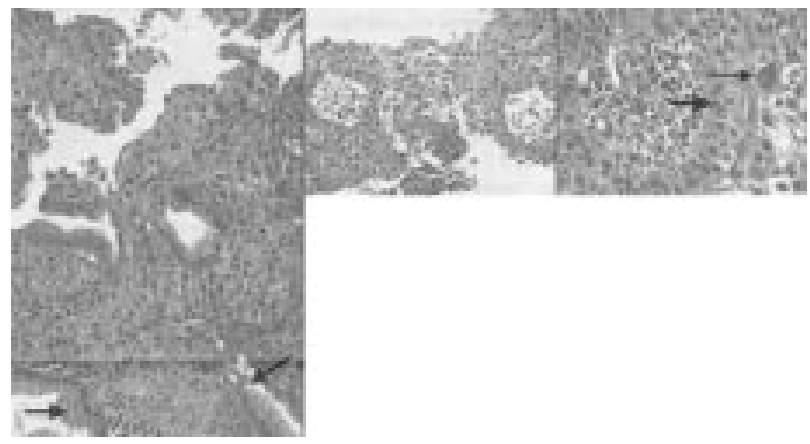

Figura 2 - Na amostra acima observa-se neoplasia escamosa infiltrando entre as glândulas (as duas setas indicam o epitélio glandular entre elas a infiltração da lâmina própria pelo epitélio escamoso). $\mathrm{Na} 1$ a imagem pequena, observa-se a neoplasia distribuída em torno de eixos conjuntivos fibrovasculares, assumindo uma configuração papilar. $\mathrm{Na} 2 \underline{a}$ imagem pequena, observam-se as características celulares das células escamosas (a seta larga indica duas células apoptóticas e a seta estreita um núcleo marcadamente atípico).

Realizou tomografia de tórax e abdome superior que evidenciou irregularidade no contorno interno da luz do cárdia, sem outros achados. Ecografia abdominal sem anormalidades, exames laboratoriais e demais exames pré-operatórios normais.

Submetida à esofagectomia transhiatal com levantamento de tubo gástrico, com boa evolução pósoperatória tendo tido alta no $12^{\circ}$ dia PO e mantendo acompanhamento ambulatorial. 0 laudo anatomopatológico da peça confirmou o diagnóstico de carcinoma epidermóide sobreposto ao esôfago de Barret (figura 3). 


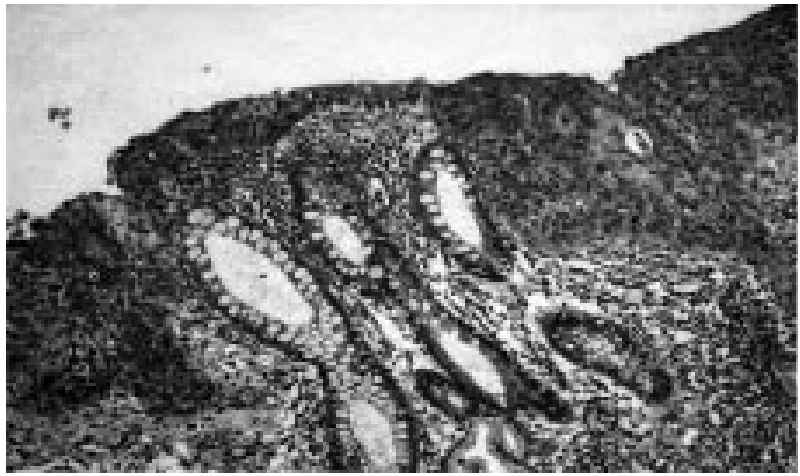

Figura 3 - Carcinoma epidermóide sobreposto à metaplasia intestinal de Barret.

\section{DISCUSSÃO}

A associação do esôfago de Barret com 0 adenocarcinoma esofágico é amplamente descrita na literatura. C asos como o apresentando neste relato não são muito freqüentes, onde o carcinoma epidermóide é encontrado associado à metaplasia intestinal. Alguns estudos demonstraram a ocorrência desse achado, como 0 de Paraf et al. ${ }^{5}$, onde foi descrito a ocorrência de cinco casos em que o carcinoma epidermóide foi encontrado juntamente com o esôfago de Barret. No entanto, nestes casos descritos, apenas um apresentava a lesão neoplásica junto ao epitélio de Barret, sendo os demais localizados na linha escamo-colunar ou acima dela ${ }^{5}$. 0 utros trabal hos também descreveram esse achado, no qual o carcinoma epidermóide foi encontrado em outra área do esôfago, distante da metaplasia intestinal ${ }^{6,7}$. Em um estudo retrospectivo realizado por Ribet e $M$ ensier ${ }^{8}$, foram realizadas 592 ressecções esofágicas por carcinoma, sendo 564 por carcinoma epidermóide. D esses, apenas dois foram encontrados imediatamente acima do esôfago de Barret, demonstrando a baixa freqüência dessa associação. Li et al. ${ }^{9}$, numa revisão de 500 casos operados por tumor de esôfago, encontraram 51 casos com a presença de esôfago de Barret, dos quais 49 eram adenocarcinomas e 2 carcinomas epidermóides sem, no entando, especificar a localização exata da neoplasia9.

No caso aqui apresentado, relatamos um achado raramente descrito na literatura e de grande interesse para o clínico/endoscopista, para o patologista e também para o cirurgião. Pacientes com diagnóstico de esôfago de Barret devem ser cuidadosamente avaliados e acompanhados, não só em relação ao já conhecido risco de evolução deste para o adenocarcinoma de esôfago, como também pela possibilidade de desenvolvimento do carcinoma epidermóide. É importante ressaltar que a investigação desses pacientes não deve ser limitada apenas à área da metaplasia, mas de todo o esôfago. A pesar de não haver nenhuma forte evidência provando a associação entre essas duas lesões, já foram relatados casos nos quais desenvolveu-se carcinoma epidermóide em outra área do esôfago, distante do epitélio de Barret, e mais raramente, como no caso apresentado pelo nosso serviço, junto a ele. Uma possível hipótese para esse acontecimento seria a presença de pequenas "ilhas" de células escamosas em meio à metaplasia intestinal. 0 crescimento da neoplasia a partir do epitélio escamoso da transição entre este e o epitélio de Barret sobre a área de metaplasia também poderia explicar este fato. M esmo esse achado sendo talvez ocasional, atentamos para a possibilidade de sua ocorrência, não justificandose que uma lesão potencialmente curável não seja identificada, principalmente quando trata-se de uma doença com tão alta morbi-mortalidade.

\section{REFERÊN CIAS}

1. Conio M, Filiberti R, Blanchi S, Giacosa A. Carditis, intestinal metaplasia and adenocarcinoma of oesophagogastric junction. Eur J Cancer Prev. 2001;10(6): 483-7.

2. Peters JH, D emeester TR. Esophagus and diaphragmatic hernia. In: Schwartz SI, editor. Principles of surgery. 7th ed. N ew York: M CG raw-H ill; 1999.

3. Shahin W, M urray JA. Esophageal cancer and Barrett's esophagus: how to approach surveillance, treatment, and palliation. Postgrad M ed. 1999;105(7):111-27.

4. Lagergren J, Bergström R, Lindgren $A, N$ yrën 0 . Symptomatic gastroesophageal reflux as risk factor for esophageal adenocarcinoma. N Engl J Med. 1999;340(11):825-31.

5. Paraf F, Flejou JF, Potet F, M olas G, FeketeF. Esophageal squamous carcinoma in five patients with Barrett's esophagus. Am J G astroenterol. 1992;87(6):746-50.

6. Rubio CA, A berg B. Barrett'smucosa in conjunction with squamous carcinoma of the esophagus. $C$ ancer. 1991;68(3):583-6.

7. Rosengard AM , H amilton SR. Squamouscarcinoma of the esophagusin patients with Barrett esophagus. M od Pathol. 1989;2(1):2-7

8. Ribet ME, M ensier EA. Reflux esophagitisand carcinoma. Surg G ynecol O bstet. 1992;175:121-5.

9. Li H , Walsh T, H ennessyT P. Carcinoma arising in Barrett's esophagus. Surg G ynecol O bstet. 1992;175:167-72. 